\title{
Prevalence of Anemia and Associated Risk Factors among Pregnant Women, What is the Role of Antenatal Care in Prevention? A Cross-sectional Study
}

\author{
Burkay Yakar $^{1}$, Edibe Pirincci ${ }^{2}$, Mehmet Onur Kaya ${ }^{3}$ and Erhan Onalan ${ }^{4}$ \\ ${ }^{1}$ Department of Family Medicine, Firat University Faculty of Medicine, Elazig, Turkey \\ ${ }^{2}$ Department of Public Health, Firat University Faculty of Medicine, Elazig, Turkey \\ ${ }^{3}$ Deparment of Biostatistics and Medical Informatics, Firat University Faculty of Medicine, Elazig, Turkey \\ ${ }^{4}$ Department of Internal Medicine, Firat University Faculty of Medicine, Elazig, Turkey
}

\begin{abstract}
Objective: To determine the prevalence of anemia with the associated factors in pregnant women and the effect of family medicine practice and antenatal care services provided by family physicians on the prevention of anemia during pregnancy.

Study Design: Community-based cross-sectional study.

Place and Duration of Study: Family Health Centres in the Elazig region, Turkey from January to June 2019.

Methodology: A total of 495 pregnant women, attending the family health centres, were included. Women were administered a questionnaire related with the anemia and related factors; and hemoglobin values were drawn. Hemoglobin concentration < $11 \mathrm{~g} / \mathrm{dl}$ was classified as anaemic. Sociodemographic, individual dietary diversity and obstetric characteristics of the participants were obtained from structured questionnaire form. Binary logistic regression model was employed to determine the effect of explanatory variables on dependent variable anemia.

Results: The prevalence of anemia during pregnancy was $27.9 \%(\mathrm{Hb}<11.0 \mathrm{gr} / \mathrm{dl})$. Prevalence of anemia was found lower in participants with higher education levels $(p=0.005)$ and having nutrition education $(p=0.004)$. Income status (OR=0.017 [95\%$\mathrm{Cl}: 0.002-0.15, \mathrm{p}<0.001])$, dark tea preference $(\mathrm{OR}=87.127[95 \% \mathrm{Cl}: 17.68-429.36, \mathrm{p}<0.001])$, and iron supplementation time $(\mathrm{OR}=0.945$ [95\% $\mathrm{Cl}: 0.91-0.98, \mathrm{p}=0.002])$ were determined as the independent predictors of anemia in pregnancy.

Conclusion: Low income, insufficient iron supplementation treatment and dark tea preference were the main predictors of anemia. Most of the factors that cause anemia during pregnancy can be prevented with patient education and supportive treatments. Therefore, the authors recommend applying effective and quality prenatal care and patient education programs to reduce anemia during pregnancy.
\end{abstract}

Key Words: Pregnant women, Anemia, Prenatal care, Family practice, Turkey.

How to cite this article: Yakar B, Pirincci E, Kaya MO, Onalan E. Prevalence of Anemia and Associated Risk Factors among Pregnant Women, What is the Role of Antenatal Care in Prevention? A Cross-sectional Study. J Coll Physicians Surg Pak 2021; 31(11):1341-1345.

\section{INTRODUCTION}

Anemia during pregnancy is a major public health problem and remains high prevalence in many countries such as Turkey. Anemia during pregnancy is the problem of both developed and developing countries. Anemia affects 16-62\% of women in developing countries and $16-29 \%$ in developed countries. ${ }^{1}$ The burden of anemia during pregnancy is highest in Africa and South-East Asia with estimated prevalence of $57.1 \%$ and $48.2 \%$, respectively; and lowest in America and Europe with prevalence of $24.1 \%$ and $25.1 \%$, respectively. ${ }^{2}$

Correspondence to: Dr. Burkay Yakar, Department of Family Medicine, Furat University, Faculty of Medicine, Elazig, Turkey

E-mail: byakar@firat.edu.tr

Received: February 20, 2020; Revised: October 27, 2020; Accepted: March 16, 2021

DOI: https://doi.org/10.29271/jcpsp.2021.11.1341
The World Health Organization reported anemia rate of $28 \%$ among pregnant women in Turkey. ${ }^{2}$ Anemia during pregnancy is a serious problem and risk for both maternal and perinatal mortality. Maternal complications include early delivery, intrauterine death, premature rupture of membranes, infections, cardiovascular diseases, reduced physical and mental strength and weakened immun system, while the some embryonic complications include prenatal anemia, preterm birth and low birth weight. ${ }^{3,4}$

Previous studies have reported significant associations among anemia during pregnancy and early age pregnancy, birth intervals, grand multiparity, low socioeconomic status, lifestyle and eating behaviors, use of iron supplementation, low educational level, and cultural differences. ${ }^{5,6}$ Therefore, the World Health Organization (WHO) gathered experts to discuss how prenatal care could potentially have a positive impact on maternal and child health outcomes, where the experts overwhelmingly agreed with this proposal. ${ }^{7}$ Previous studies have also high- 
lighted the need for a prenatal nutritional care system that emphasises better use of essential nutrients, including iron, minerals, and vitamins with high biological value, and emphasises the conduct of modified interventions to control the prevalence and severity of anemia among pregnant women. ${ }^{8,9}$

Understanding the prevalence, associated factors, applications to prevent anemia such as antenatal care and their complex interaction may ease the interventions to lessen the case burden of anemia during pregnancy.

The first aim of this study was to determine the prevalence of anemia and related factors in pregnant women; as well as to investigate the effect of family practice and antenatal care services provided by family physicians on the prevention of anemia during pregnancy.

\section{METHODOLOGY}

Community based cross-sectional study was conducted in Elazig district, Eastern Turkey from January-June2019, in accordance with the Helsinki Declaration and after the Ethical Research Committee approval (22.03.2018, IRB Number: 06/04). Informed consents were obtained from all patients.

At the beginning of the study, there were 142 family physicians in 55 family health centres in the city centre of Elazig. The total population registered to family physicians was 449185, of which 3228 were pregnant women. The formula " $n=N t^{2} p q / d^{2}(N-1)+t^{2} p q$ " was used to calculate the sample size. The prevalence of anemia in pregnancy has been reported by the WHO as $28 \%$ in Turkey. The minimum sample size was found 282 pregnant women $(\mathrm{N}=3228$, $t=1.96, p=28 \%, q=72 \%$, and $d=0.05$ ). The number of pregnant women to be taken from the family health centres were calculated according to the total number of pregnant women in each family health centres. Pregnant women were included in the study by simplerandom sampling method, according to the numberofpregnant women to be taken from each family health centres. In this study of 495 pregnant women, inclusion criteria for enrollment included; pregnancy, being over 18 years and volunteering. Exclusion criteria for the study were diagnosed eclampsia, pre-eclampsia, diabetes mellitus, hypertension, sickle cell disease, any congenital hemoglobin disorders, with hearing and vision problems as well as mental disorder.

Data were collected using pretested structured questionnaire by face-to-face interview. Sociodemographic, nutrition, antenatal care and pregnancy characteristics of the participants were questioned with the questionnaire forms. Hemoglobulin values of pregnant women were obtained from examinations performed during routine pregnancy follow-up of family physicians. According to the WHO categories for hemoglobin concentration values, pregnant women were grouped into one of two categories: no anemia $(\geq 11.0 \mathrm{~g} / \mathrm{dl})$ and anemia $(\mathrm{Hb}<11.0 \mathrm{~g} / \mathrm{dl}){ }^{2}$

The minimum wage is 2400 Turkish lira ( $T L$ ) in Turkey during study time. Household income was grouped lower than 2000 TL as bad, between 2000-4000 TL as medium and over than 4000 TL as good. In our study, participants were asked to group household income as low, medium and good. Women dietary diversity scores were computed based on quide for Turkish dieticians patient follow-up. ${ }^{10}$ The patient follow-up guide for dieticians recommends the consumption of 3 main meals and 3 snacks for the need for increased energy and nutrients in pregnant women. Therefore, the number of daily meals of the participants was first questioned. Five types of food (i-meat and fish, ii-eggs, iii-cereals, iv-vegetables, v-fresh and dried fruits) that participants should eat for daily iron needs were questioned. All participants were told about the portion amounts of five groups of food and the portion amounts of each group of foods in the last week were questioned. Participants were asked to identify the food portions they consumed. The amount of tea consumption, prepared by hot brewing method, was calculated as the specified cups. Tea preferences of the participants were evaluated in two groups as light or dark tea. The consumed tea was recorded as light or dark tea, according to the participants' own perceptions. A previous study shows that tea consumed simultaneously with an iron-containing porridge meal leads to decreased nonheme iron absorption and that a 1-h time interval between a meal and tea consumption attenuates the inhibitory effect, resulting in increased nonheme iron absorption. So we asked the participants tea consumption time as "within 1 hour after meals" or "at least 2 hours aftermeals". ${ }^{11}$

Statistical analysis of the data was performed using IBM SPSS 22 statistical package programme. Shapiro-Wilk test was used to determine whether the data showed normal distribution. Descriptive statistics of the data are indicated as Mean \pm S.D and [Median (quartile 1-quartile 3 ) for continuous data, as frequency and percentage [n (\%)] for categorical variables. Chi-square test was used for categorical data. Mann-Whitney U-test was used to compare two independent groups for nonnormally distributed continuous data. In order to determine the effect of independent variables on dependent variable, the binary logistic regression model with backward stepwise were used. Significance level was $\alpha=0.05$.

\section{RESULTS}

The final total sample was 495 pregnant women. The mean age of participants was $30.06 \pm 5.15$ years. The prevalence of anemia during pregnancy was $27.9 \%(n=138)$. The prevalence of anemia in the third trimester was higher than the $1^{\text {st }}$ and $2^{\text {nd }}$ trimesters $(p<0.001)$. The results of bivariate analyses showed that anemia was significantly associated with sociodemographic characteristics, such as lower educational level $(p=0.005)$, housewife status $(p=0.018)$, those who prefer dark tea $(p<0.001)$ and drink tea within one hour after a meal $(p<0.001)$, trimester period $(p<0.001)$ and participants who do not receive nutrition education $p=0.004$, Table $\mathrm{I}$.

Anemia was statistically associated with age $(p=0.001)$, gravida $(p<0.001)$, low number of meats portion $(p<0.001)$, vegetables portions $(p<0.001)$ and weekly total portions $(p=0.006)$ (Table II). 


\begin{tabular}{|c|c|c|c|c|c|c|c|}
\hline \multirow{2}{*}{ Characteristics } & \multicolumn{2}{|l|}{ Anemic } & \multicolumn{2}{|c|}{ Non-anemic } & \multicolumn{2}{|l|}{ Total } & \multirow[b]{2}{*}{ p-value } \\
\hline & $n=138$ & $\%$ & $n=357$ & $\%$ & $n=495$ & $\%$ & \\
\hline \multicolumn{8}{|l|}{ Educational status } \\
\hline Primary education & 27 & 19.6 & 36 & 10.1 & 63 & 12.7 & \multirow{4}{*}{0.005} \\
\hline Secondary education & 22 & 15.9 & 59 & 16.5 & 81 & 16.4 & \\
\hline High school & 51 & 37.0 & 114 & 31.9 & 165 & 33.3 & \\
\hline University & 38 & 27.5 & 148 & 41.5 & 186 & 37.6 & \\
\hline \multicolumn{8}{|l|}{ Occupation } \\
\hline House wife & 107 & 77.5 & 231 & 64.7 & 338 & 68.3 & \multirow{3}{*}{0.018} \\
\hline Minimum wage employee & 21 & 15.2 & 94 & 26.3 & 115 & 23.2 & \\
\hline Official & 10 & 7.2 & 32 & 9.0 & 42 & 8.5 & \\
\hline \multicolumn{8}{|l|}{ Income perception } \\
\hline Bad & 13 & 9.4 & 20 & 5.6 & 33 & 6.7 & \multirow{3}{*}{0.303} \\
\hline Medium & 101 & 73.2 & 269 & 75.4 & 370 & 74.7 & \\
\hline Good & 24 & 17.4 & 68 & 19.0 & 92 & 18.6 & \\
\hline \multicolumn{8}{|c|}{ Tea or coffee consumption status } \\
\hline Non-drinker & 9 & 6.5 & 39 & 10.9 & 48 & 9.7 & \multirow[b]{2}{*}{0.138} \\
\hline Drinker & 129 & 93.5 & 318 & 89.1 & 447 & 90.3 & \\
\hline \multicolumn{8}{|l|}{ Tea preferences } \\
\hline Light tea & 34 & 26.4 & 294 & 92.5 & 328 & 73.4 & \multirow{2}{*}{$<0.001$} \\
\hline Dark tea & 95 & 73.6 & 24 & 7.5 & 119 & 26.6 & \\
\hline \multicolumn{8}{|l|}{ Tea consumption time } \\
\hline Only for breakfast & 69 & 53.5 & 248 & 78.0 & 317 & 70.9 & \multirow{3}{*}{$<0.001$} \\
\hline Within 1 hour after meals & 55 & 42.6 & 38 & 11.9 & 93 & 20.8 & \\
\hline At least 2 hours after meals & 5 & 3.9 & 32 & 10.1 & 37 & 8.3 & \\
\hline \multicolumn{8}{|l|}{ Trimester } \\
\hline 1.trimester & 15 & 10.9 & 82 & 23.0 & 97 & 19.6 & \multirow{3}{*}{$<0.001$} \\
\hline 2.trimester & 60 & 43.5 & 170 & 47.6 & 230 & 46.5 & \\
\hline 3.trimester & 63 & 45.7 & 105 & 29.4 & 168 & 33.9 & \\
\hline \multicolumn{8}{|l|}{ Iron pill usage status } \\
\hline Use & 50 & 36.2 & 146 & 40.9 & 196 & 39.6 & \multirow{2}{*}{0.341} \\
\hline Not use & 88 & 63.8 & 211 & 59.1 & 299 & 60.4 & \\
\hline \multicolumn{8}{|l|}{ Nutrional education status } \\
\hline Have & 68 & 49.3 & 226 & 63.3 & 294 & 59.4 & \multirow{2}{*}{0.004} \\
\hline Have not & 70 & 50.7 & 131 & 36.7 & 201 & 40.6 & \\
\hline
\end{tabular}

Table II: Relationship between number of pregnancy, iron supplementation time, number of portions with anemia.

\begin{tabular}{|c|c|c|c|c|c|}
\hline \multirow{2}{*}{ Variables } & \multicolumn{2}{|l|}{ Anemic } & \multicolumn{2}{|c|}{ Non-anemic } & \multirow{2}{*}{ p-value } \\
\hline & Median & $(Q 1-Q 3)^{* *}$ & Median & $(\text { Q1-Q3) })^{* *}$ & \\
\hline Age & 31 & $(26.75-35)$ & 29 & $(26-32)$ & 0.001 \\
\hline Gravida & 3 & $(2-3)$ & 2 & $(1-3)$ & $<0.001$ \\
\hline Number of prenatal care follow-up & 3 & $(2-4)$ & 2 & $(2-3)$ & 0.008 \\
\hline Iron supplementation time (month) & 4 & $(3-6)$ & 3 & $(2-5)$ & 0.015 \\
\hline Number of meals per day & 3 & $(3-4)$ & 3 & $(3-4)$ & 0.715 \\
\hline Portion amounts of meat & 1 & $(1-2)$ & 3 & $(2-3)$ & $<0.001$ \\
\hline portion amounts of eggs & 2 & $(1-2)$ & 2 & $(1-2)$ & 0.924 \\
\hline portion amounts of cereals & 1 & $(1-2)$ & 2 & $(2-3)$ & 0.107 \\
\hline portion amounts of vegetables & 3 & $(2-4)$ & 7 & $(3-7)$ & $<0.001$ \\
\hline portion amounts of fruits & 1 & $(1-2)$ & 1 & $(1-2)$ & 0.172 \\
\hline Total number of portion per week & 17 & $(5-20)$ & 18 & $(5-24)$ & 0.006 \\
\hline
\end{tabular}

Table III: Binary logistic regresyon results.

\begin{tabular}{|c|c|c|c|}
\hline Variable & Odds Ratios & Confidence Interval (95.0\%) & p-value \\
\hline Income (medium) & 0.017 & $0.002-0.15$ & $<0.001$ \\
\hline Income (good) & 0.29 & $0.058-1.451$ & 0.132 \\
\hline Tea preferences & 87.127 & $17.68-429.36$ & $<0.001$ \\
\hline Iron supplementation time & 0.945 & $0.912-0.980$ & 0.002 \\
\hline
\end{tabular}

In the $9^{\text {th }}$ step analysis of stepwise logistic regression analysis, which included all the factors associated with anemia, income status $(p<0.001)$, dark tea preference $(p<0.001)$ and duration of iron supplementation time $(p=0.002)$ were found to be statistically associated with anemia (Table III).

\section{DISCUSSION}

The current study finding showed that the prevalence of anemia during pregnancy was $27.9 \%$. The prevalence of anemia during pregnancy was reported $28 \%$ by WHO in Turkey. ${ }^{2}$ The preva- 
lence of anemia during pregnancy was reported as $28.8 \%$, $28.6 \%$ and $32.1 \%$ in Turkey. ${ }^{12-14}$ The findings were consistent with the data of authors' country.

Socio-demographic factors of gestational age, maternal age, income level, parity and occupation of the mother were associated with the risk of anemia during pregnancy. These findings are similar to the previously reported study data. ${ }^{8,15}$ Various studies reported that poverty decreases, if women work and this positively affects their health status. ${ }^{16}$ Unemployment and low education levels may affect household income negatively, so the effect of these factors on income should not be ignored. The findings of the authors and literature data suggest that anemia can be reduced by increasing socioeconomic status and income levels.

According to the the findings of this study, having nutritional education, iron supplementation time, tea consumption, portion amount of meat and vegetable consumption were determined as factors related to anemia during pregnancy. The two different meta-analyses reported that nutritional education status, iron supplementation time and nutritional variety were determinants of anemia in pregnancy. ${ }^{17,18}$ Berhe et al. reported that pregnant women, who consumed low diversified diet, were at high risk of anemia; and drinking coffee or tea with a meal or immediately after a meal increases the development of anemia during pregnancy. ${ }^{9}$ In this sense, the findings of this study support the data in the literature. Therefore, nutritional habits, knowledge levels and awareness of pregnant women were associated factors with anemia, except for sociodemographic characteristics.

In family medicine practice, prenatal care service is provided to pregnant women by family physicians four times in Turkey. Nutritional counselling, periodic health examination, and supportive therapy (iron and vitamin D supplement) are routinely offered. Pirincci et al. reported that $42.4 \%$ prevalence of anemia in pregnant women in their study before family medicine practice in Elazig. ${ }^{19}$ In the current study, conducted in the same centre, the prevalence of anemia in pregnant women was found to be $27.9 \%$. After the study of Pirincci et al., Family medicine practice and free iron supplementation treatment for pregnant women started in Turkey. Comparing the current study data with the study of Pirincci et al., it was thought that prenatal care services provided by family physicians could contribute to reducing the factors associated with anemia during pregnancy. ${ }^{19}$ Although the effects of family physicians on socio-demographic factors causing anemia are limited, they may prevent other anemia related factors such a nutritional habits, awareness and supportive treatment with antenatal care service.

The first limitation of this study was that it was cross-sectional, and performed in only one region, as a result, it could not represent the whole country. In this study, the factors that could affect the anemia were the participants' own statements, which may have led to the failure to provide stan- dardization in the portion evaluation of the foods consumed by the participants. Another limitation was that the authors did not measure the level of nutritional knowledge of the participants, but questioned whether they received nutritional education. This limited this research on the effect of antenatal care on participants' knowledge level.

\section{CONCLUSION}

In this study, low income, insufficient iron supplementation treatment, and dark tea preference were the main predictors of anemia. Adherence of supportive treatments and nutritional habits of patients are one of the most important determinants of anemia. At the same time, high education level and having nutrition education were found to have a protective effect from anemia. Based on all these findings, the authors recommend the administration antenatal care service and patient education programs to reduce anemia during pregnancy.

\section{ETHICAL APPROVAL:}

The study was approved by local Ethics Committee of Fırat University Non-Invasive Research Ethics Committee.

\section{PATIENTS' CONSENT:}

The informed consents were obtained from all patients.

\section{CONFLICT OF INTEREST:}

The authors declared no conflict of interest.

\section{AUTHORS' CONTRIBUTION:}

BY, EP, MOK, EO: Designed this study and prepared this manuscript.

BY, MOK, EO: Collected and analysed clinical data.

BY, EP: Significantly revised this manuscript.

\section{ACKNOWLEDGEMENTS:}

The authors thank all family doctors in Elazig region who helped us in the study.

\section{REFERENCES}

1. Stevens GA, Finucane MM, De-Regil LM, Paciorek CJ, Flaxman SR, Branca F,et al. Global, regional, and national trends in haemoglobin concentration and prevalence of total and severe anaemia in children and pregnant and nonpregnant women for 1995-2011: A systematic analysis of population-representative data. Lancet Glob Health 2013; 1(1):e16-25. doi.org/10.1016/s 2214109x(13) 70001-9.

2. WHO. The global prevalence of anaemia in 2011. Accessed September 15th, 2019 at: http://apps.who.int/iris/ bitstream/handle/ 10665/177094/9789241564960_eng.pdf

3. Jung J, Rahman MM, Rahman MS, Swe KT, Islam MR, Rahman MO, et al. Effects of hemoglobin levels during pregnancy on adverse maternal and infant outcomes: A systematic review and meta-analysis. Ann NY Acad Sci 2019; 1450(1):69-82. doi.org/10.1111/nyas.14112.

4. Rahman MM, Abe SK, Rahman MS, Kanda M, Narita S, Bilano $V$, et al. Maternal anemia and risk of adverse birth and 
health outcomes in low- and middle-income countries: Systematic review and meta-analysis. Am J Clin Nutr 2016; 103(2):495-504. doi.org/10.3945/ajcn.115.107896.

5. Ullah A, Sohaib M, Saeed F, Iqbal S. Prevalence of anemia and associated risk factors among pregnant women in Lahore, Pakistan. Women Health 2019; 59(6):660-71. doi.org/10.1080/03630242.2018.1544966.

6. Di Renzo GC, Spano F, Giardina I, Brillo E, Clerici G, Roura LC. Iron deficiency anemia in pregnancy. Womens Health (Lond) 2015; 11(6):891-900. doi.org/10.2217/whe.15.35.

7. World Health Organization. Meeting to Develop a Global Consensus on Preconception Care to Reduce Maternal and Childhood Mortality and Morbidity; 6-7 February 2012 Meeting Report; World Health Organization: Geneva, Switzerland, 2013.

8. Mahamoud NK, Mwambi B, Oyet C, Segujja F, Webbo F, Okiria JC, et al. Prevalence of anemia and its associated socio-demographic factors among pregnant women attending an antenatal care clinic at kisugu health center IV, Makindye division, Kampala, Uganda. J Blood Med 2020; 11:13-18. doi.org/10.2147/JBM.S231262.

9. Berhe K, Fseha B, Gebremariam G, Teame H, Etsay N, Welu $G$, et al. Risk factors of anemia among pregnant women attending antenatal care in health facilities of eastern zone of tigray, ethiopia, case-control study, 2017/18. Pan Afr Med J 2019; 34:121. doi.org/10.11604\%2Fpamj.2019.34. 121.15999.

10. Sanlier N, Yaparevi EG, Soylu MK. Nutrition counseling program of Individual standard for weight management in pregnant women. In: Rakıcıoglu N, Samur G, Basoglu S, eds. Patient monitoring guide weight management handbook for dieticians. Ankara: Turkish Public Health Association 2017:177-222. doi.org/10.1097/aog.00000000 00000416.

11. Ahmad Fuzi SF, Koller D, Bruggraber S, Pereira DI, Dainty JR, Mushtaq S. A 1-h time interval between a meal containing iron and consumption of tea attenuates the inhibitory effects on iron absorption: A controlled trial in a cohort of healthy UK women using a stable iron isotope. Am J Clin
Nutr 2017; 106(6):1413-21. doi.org/10.3945/ ajcn.117. 161364.

12. Taner CE, Ekin A, Solmaz U, Gezer C, Cetin B, Kelesoglu M, et al. Prevalence and risk factors of anemia among pregnant women attending a high-volume tertiary care center for delivery. J Turk Ger Gynecol Assoc 2015; 16(4):231-6. doi.10.5152/jtgga.2015.15071.

13. Kavak EÇ, Kavak SB. The association between anemia prevalence, maternal age and parity in term pregnancies in our city. Perinatal J 2017; 25(1):6-10. doi.org/10.2399/ prn.17.0251002.

14. Göker A, Yanıkerem E, Birge Ö. Prevalence of anemia in pregnant women who applied to a training and Research Hospital in Manisa: A retrospective study. STED 2012; 21(3):102-9.

15. Dairo MD, Lawoyin TO. Socio-demographic determinants of anaemia in pregnancy at primary care level: A study in urban and rural Oyo State, Nigeria. Afr J Med Med Sci 2004; 33(3):213-7. http://pubmed.ncbi.nlm.nih.gov/15819466/.

16. Obai G, Odongo P, Wanyama R. Prevalence of anaemia and associated risk factors among pregnant women attending antenatal care in Gulu and Hoima regional hospitals in Uganda: A cross sectional study. BMC Pregnancy Childbirth 2016; 16(1):76. doi.org/10.1186/s12884-016-0865-4.

17. Kassa GM, Muche AA, Berhe AK, Fekadu GA. Prevalence and determinants of anemia among pregnant women in Ethiopia: A systematic review and meta-analysis. BMC Hematol 2017; 17:17. doi.org/10.1186/s12878-017-0090-z.

18. Lassi ZS, Kedzior SG, Tari W, Jadoon Y, Das JK, Bhutta ZA. Effects of preconception care and periconception interventions on maternal nutritional status and birth outcomes in low- and middle-ıncome countries: A systematic review. Nutrients 2020; 12(3). pii: E606. doi.org/10.3390/ nu12030606.

19. Pirincci E, Acik Y, Bostanci M, Eren S, Beritanli H. Prevalence of anemia in pregnant Women in Elazığ. Fırat Uni Med J Health Sci 2001; 15(3):449-54. 